\title{
Evaluation of Urinary Calcium Creatinine Ratio in Pre-Eclampsia
}

\section{INDU PRASAD, BANDANA KUMARI, ACHAL NARAYAN ROY, PRITAM PRAKASH}

\section{ABSTRACT}

Introduction: Hypertensive disorder complicates the pregnancy. The exact aetiology of hypertensive disorders of the pregnancy is still unknown and management is controversial.

Aim: To evaluate the role of urinary Calcium Creatinine Ratio (CCR) as a marker in early diagnosis of pre-eclampsia.

Materials and Methods: Urinary calcium creatinine ratio was determined in a random sample of urine in 100 patients of pre-eclampsia (Study group) and 100 normotensive pregnant (Control group) patients of gestational age 20-
36 weeks. Cut off value for CCR was taken as $\leq 0.04$. Comparative study was done by using chi-square test.

Results: In study group, $89 \%$ of the cases had urinary $\mathrm{CCR} \leq 0.04$. Amongst the controls only $6 \%$ of the cases had CCR $\leq 0.04$. Statistically, CCR as high risk factor for early diagnosis of pre-eclampsia was significant $(p<0.001$ and ' $r$ ' = 0.169).

Conclusion: The result showed lower urinary calcium excretion and low CCR in pre-eclamptic patients than normotensive pregnant women.

Keywords: Hypertensive, Mortality, Normotensive

\section{INTRODUCTION}

Despite of so much research and changes in management, pre-eclampsia is still a leading cause of maternal morbidity and mortality in India and worldwide. About $5-7 \%$ of the pregnancies are affected by pre-eclampsia and hypertensive disorders [1]. Pre-eclampsia is a "multisystem disorder". Pathology behind pre-eclampsia is reduced perfusion of organs due to vasospasm. It is usually associated with proteinuria or oedema or both. In spite of extensive research, the mechanism how pregnancy initiates or aggravates hypertension remains unknown. It is amongst the most significant unsolved problems in obstetrics. This is the disorder of widespread vascular endothelial malfunction and vasospasm which occurs after 20 weeks of gestation and presents till 4-6 weeks postpartum.

Hypertension is diagnosed when systolic blood pressure is greater than $140 \mathrm{mmHg}$ and diastolic blood pressure greater than $90 \mathrm{mmHg}$ on two successive measurements done 4-6 hours apart or when systolic blood pressure is increased by $30 \mathrm{mmHg}$ and diastolic blood pressure by $15 \mathrm{mmHg}$. Proteinuria is defined as excretion of $300 \mathrm{mg}$ or more of protein in 24 hour urine sample or $\geq 1+$ dipstick in a random sample of urine. Further pre-eclampsia can progress to eclampsia leading to seizures and HELLP syndrome if left untreated. It can also lead to haemorrhage and infection, resulting in significant maternal morbidity and mortality. Various predictors have been proposed e.g. roll-over test, second trimester mean arterial pressure test, serum uric acid test, angiotensinogen sensitivity test, Isometric test etc. But none of them have been proved ideal either because of high incidence of false positivity or their complexity in result interpretation. It has been found that decreased urinary excretion of calcium may be considered as a useful tool for the early diagnosis of pre-eclampsia [2]. This disorder is highly prevalent in our country in spite of great advances in obstetrics. So, the present work is focused on prevention of the disease rather than treatment. Therefore, the study was done to determine the relationship between pre-eclampsia, hypocalciuria and calcium to creatinine ratio for early prediction of pre-eclampsia in a random urine sample.

\section{AIM}

To evaluate calcium: creatinine ratio for the early diagnosis of pre-eclampsia so as to avoid maternal and fetal morbidity and mortality in the society.

\section{MATERIALS AND METHODS}

A case control study was undertaken in the Department of Biochemistry, Patna Medical College and Hospital, Patna, Bihar in the year 2010-2011. 
It was carried out on a total number of 200 women of gestational age 20-36 weeks attending the antenatal clinic (outdoor), or admitted in the ward or in labour room in the Obstetrics and Gynaecology Department, Patna Medical College and Hospital, Patna, Bihar, India.

For statistical significance and comparison, these were divided into two groups.

Group I: (Study group)- Study group consists of 100 patients of pre eclampsia. These patients had the following signs present-

(1) Blood Pressure 140/90 mmHg or more.

(2) Proteinuria- Tested with Dipstick $\geq 1+$ dipstick in random sample of urine.

Group II : (Control group)- Control group consisted of 100 normotensive pregnant patients of gestational age 20-36 weeks attending the routine antenatal clinic, ward, or in labour room in the Obstetrics and Gynaecology Department, who had no risk factors for the development of pre eclampsia like; history of pregnancy induced hypertension in the past pregnancy, history of twin pregnancy in the present or past pregnancy or in the family.

Subjects with any history of hypertension, diabetes mellitus, chronic renal disease, immunological or vascular disorders were excluded.

\section{Urine Sample Analysis}

Random sample of urine was taken as specimen and analyzed by the semi-auto analyzer (colorimetric method) for the estimation of urinary calcium and urinary creatinine and ratio.

Laboratory test of urine for estimation of calcium: Urinary calcium was analysed by OCPC (O-Cresolphthalein Complex one) method colorimetrically [3].

Calcium + OCPC $\rightarrow$ Bluish- Purple Complex

\section{Calculation:}

Urine calcium $(\mathrm{mg} / \mathrm{dl})=$ Absorbance of Test $X 10 \times$ Dilution Factor Absorbance of Standard

Normal urinary excretion of calcium $=100-300 \mathrm{mg} /$ day.

Laboratory test of Urine for Estimation of Creatinine: Urinary creatinine was estimated by Jaffe's Method (Alkaline Picrate) at 520nm [4].

\section{Calculation:}

Urinary Creatinine in $\mathrm{g} / \mathrm{L}=\mathrm{OD}$ of Test-OD of Blank $\times 0.75$

$$
\text { OD of Standard - OD of Blank }
$$

Where, "OD" is Optical Density.

Result obtained was multiplied by 10 to convert it in $\mathrm{mg} / \mathrm{dl}$. Normal urinary creatinine excretion $=1-2$ gm/day.
Reagents Used: Commercially available kits provided by Span Diagnostic Company of India were used for both the parameters.

All the collected data was reviewed and analysed for urinary calcium-creatinine ratio (CCR) in both the study and control groups.

So, the ratio is given as

$$
\begin{aligned}
& \text { Urinary Calcium }(\mathrm{mg} / \mathrm{dl}) \\
& \text { Urinary Creatinine }(\mathrm{mg} / \mathrm{dl})
\end{aligned}
$$

Cut off for CCR is taken as $\leq 0.04$ [5].

\section{STATISTICAL ANALYSIS}

The results obtained were further analysed for SD, t- test,SEM and $p$ value. The $p$ value $<0.001$ was considered significant. Comparative study was done by using chi-square test.

\section{RESULTS}

The study done was a case control study conducted on 200 pregnant women, containing 100 pre-eclamptic patients in the case and 100 normotensive pregnant women in the control group. In the study group 52\% patients were primigravida [Table/Fig-1]. Most of the patients (75\%) belonged to the age group of 16-25 years [Table/Fig-2].

Urinary calcium excretion in pre-eclamptic group was found to be as $4.8 \pm 1.52 \mathrm{mg} / \mathrm{dl}$ and $5.26 \pm 1.91 \mathrm{mg} / \mathrm{dl}$ in the age group 16-25 years and 26-36 years respectively. It was compared with urinary calcium excretion of the patients of same age interval in the control group $(12.33 \pm 3.58 \mathrm{mg} / \mathrm{dl}$ and $12.34 \pm 2.79 \mathrm{mg} / \mathrm{dl}$ resp). This was found to be lower in pre-eclamptic group with $\mathrm{p}<0.001$ [Table/Fig-3].

Similarly, urinary creatinine excretion in the pregnant preeclamptic women was found to be as125.69 $\pm 14.56 \mathrm{mg} / \mathrm{dl}$

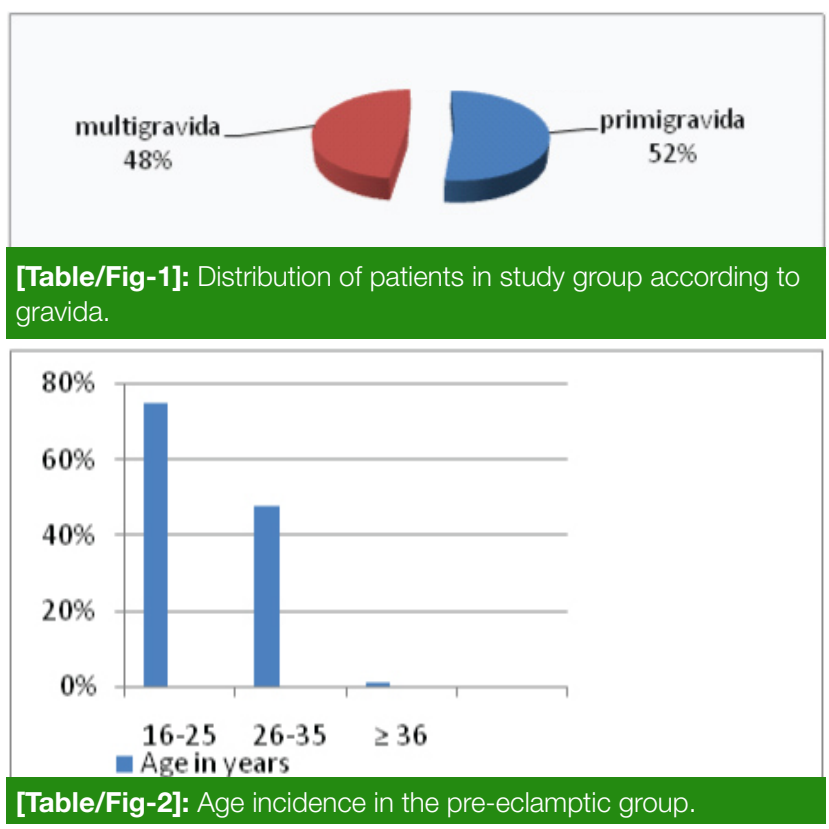




\begin{tabular}{|c|c|c|c|c|c|c|c|}
\hline \multirow[t]{2}{*}{ Group } & \multirow{2}{*}{$\begin{array}{l}\text { Age Interval } \\
\text { (Years) }\end{array}$} & \multirow[t]{2}{*}{$\mathrm{N}$} & \multicolumn{3}{|c|}{ Urinary Calcium Excretion (mg/dl) } & \multirow[t]{2}{*}{$\mathrm{t}$} & \multirow[t]{2}{*}{$p$} \\
\hline & & & Mean & SD & SEM & & \\
\hline Study & $16-25$ & 5 & 4.8 & 1.52 & 0.17 & \multirow[t]{2}{*}{16.11} & \multirow[t]{2}{*}{$<0.001$} \\
\hline Control & $16-25$ & 48 & 12.33 & 3.58 & 0.51 & & \\
\hline Study & $26-36$ & 25 & 5.26 & 1.91 & 0.39 & \multirow[t]{2}{*}{11.25} & \multirow[t]{2}{*}{$<0.001$} \\
\hline Control & $26-36$ & 52 & 12.34 & 2.79 & 0.38 & & \\
\hline
\end{tabular}

[Table/Fig-3]: Urinary calcium excretion in different age groups.

\begin{tabular}{|c|c|c|c|c|c|c|c|}
\hline \multirow[t]{2}{*}{ Group } & \multirow{2}{*}{$\begin{array}{c}\text { Age Interval } \\
\text { (Years) }\end{array}$} & \multirow[t]{2}{*}{$\mathrm{N}$} & \multicolumn{3}{|c|}{ Urinary Calcium Excretion (mg/dl) } & \multirow[t]{2}{*}{$\mathrm{t}$} & \multirow[t]{2}{*}{$\mathrm{p}$} \\
\hline & & & Mean & SD & SEM & & \\
\hline Study & $16-25$ & 75 & 125.69 & 14.56 & 1.69 & \multirow[t]{2}{*}{3.4} & \multirow[t]{2}{*}{$<0.001$} \\
\hline Control & $16-25$ & 48 & 133.80 & 12 & 1.73 & & \\
\hline Study & $26-36$ & 25 & 127.62 & 14.69 & 1.98 & \multirow[t]{2}{*}{4.4} & \multirow[t]{2}{*}{$<0.001$} \\
\hline Control & $26-36$ & 52 & 134.83 & 12.52 & 2.2 & & \\
\hline
\end{tabular}

[Table/Fig-4]: Urinary creatinine excretion in different age groups.

\begin{tabular}{|l|c|c|c|c|c|c|}
\hline Group & $\mathrm{N}$ & \multicolumn{3}{|c|}{$\begin{array}{c}\text { Urinary Calcium } \\
\text { Excretion(mg/dl) }\end{array}$} & $\mathrm{t}$ & $\mathrm{p}$ \\
\cline { 3 - 5 } & & mean & SD & SEM & & \\
\hline Study & 100 & 4.91 & 1.62 & 0.16 & 21.07 & $<0.001$ \\
\hline Control & 100 & 12.43 & 3.18 & 0.31 & & \\
\hline
\end{tabular}

[Table/Fig-5]: Urinary calcium excretion in pre-eclamptic group.

\begin{tabular}{|l|c|c|c|c|c|c|}
\hline Group & $\mathrm{N}$ & \multicolumn{3}{|c|}{$\begin{array}{c}\text { Urinary Calcium } \\
\text { Excretion(mg/dl) }\end{array}$} & \multirow{2}{*}{$\mathrm{t}$} & $\mathrm{p}$ \\
\cline { 3 - 5 } & & mean & SD & SEM & & \\
\hline Study & 100 & 120.53 & 14.31 & 14.31 & 5 & $<0.01$ \\
\hline Control & 100 & 130.64 & 12.50 & 12.5 & & \\
\hline
\end{tabular}

\begin{tabular}{|c|c|c|c|c|c|}
\hline \multirow[t]{2}{*}{ Group } & \multicolumn{2}{|c|}{ Urinary Calcium } & \multicolumn{2}{|c|}{ Urinary Creatinine } & \multirow{2}{*}{$\begin{array}{c}\text { Co-relation } \\
\text { Co-efficient } \\
\text { (r) }\end{array}$} \\
\hline & Mean & SD & Mean & SD & \\
\hline Study (100) & 4.91 & 1.62 & 120.53 & 14.31 & \multirow[t]{2}{*}{0.169} \\
\hline Control (100) & 12.43 & 3.18 & 130.18 & 12.50 & \\
\hline
\end{tabular}

[Table/Fig-7]: Co-relation between calcium and creatinine excretion. $p=0.058$

\begin{tabular}{l|c|c|}
\hline Group (N) & CCR $\leq 0.004$ & CCR $>0.004$ \\
\hline Study (100) & $89 \%$ & $11.0 \%$ \\
\hline Control (100) & $6 \%$ & $94.0 \%$ \\
\hline
\end{tabular}
[Table/Fig-8]: Distrubution of patients on the basis of CCR.
Chi square $\left(X^{2}\right)=138.13, p<0.001$

and $127.62 \pm 14.69 \mathrm{mg} / \mathrm{dl}$ respectively in the age group 16 25 years and $26-36$ years. It was found to be lower than that in the controls $(133.80 \pm 12$ and $134.83 \pm 12.52) \mathrm{mg} / \mathrm{dl}$. This value was again significant with $\mathrm{p}<0.001$ [Table/Fig-4].

In pre-eclamptic group mean urinary calcium was $4.91 \mathrm{mg} /$ $\mathrm{dl}$ which was lower than the mean value of control group (12.43 mg/dl) [Table/Fig-5].
Mean urinary creatinine in the pre-eclamptic group and normotensive group were $120.53 \mathrm{mg} / \mathrm{dl}$ and $130.64 \mathrm{mg} / \mathrm{dl}$ respectivley [Table/Fig-6].

The correlation coefficient ' $r$ ' was equal to 0.169 between both study and control groups [Table/Fig-7]. Amongst the study group $89 \%$ of the patients had CCR $\leq 0.004$ [Table/ Fig-8]. Chi square $\left(\chi^{2}\right)$ value was 138.13 showing that ratio is highly significant $(p<0.001)$.

\section{DISCUSSION}

The present study showed that $89 \%$ of the pre-eclamptic women had CCR $\leq 0.004$. When calculated statistically, it was found that CCR alone can be taken as high risk factor for pre-eclampsia. The cut off value $(C C R \leq 0.04)$ was similar with that of various studies [1,5-9]. It is observed that the urinary excretion of calcium and creatinine is increased during pregnancy but when pregnancy is associated with high risk factors like hypertension, their excretion is reduced resulting in development of pre-eclampsia. Hence, a definite relationship was found between low calcium creatinine ratio and development of pre-eclampsia.

Result of the present study corresponds with the result of Gaurang K et al., [1], Mittal Shilpa et al., [10], Kazemi AFN et al., [11] Taufield et al., [12], Tufan Bilgin et al., [13], Segovia $\mathrm{BL}$ et al., [14], Ingec $\mathrm{M}$ et al., [15], Halhali $\mathrm{A}$ et al., [16], Dasgupta Mandira et al., [17], Sirohiwal Daya et al.,[18], Donovan et al., [19], Sheela CN et al., [7]. They estimated that calcium excretion in pre-eclampsia was significantly lower than in normal pregnant women. The result obtained in the present study is more or less similar to the finding noted above. During normal pregnancy, body physiologically compensates for increased calcium demand by either increasing the intestinal absorption or by decreasing the loss by renal mechanisms. But changes in the renal function 
may lead to increased reabsorption of calcium by the distal tubules of kidney [20]. These mechanisms, thus, lead to hypocalciuria in women destined to develop pre-eclampsia.

While others noted decrease of urinary creatinine in preeclampsia, Mittal Shilpa et al., [10], Kazemi AFN et al., [11] and Moni SY et al., [21] observed increase in urinary creatinine in pre-eclamptic patients.

Sera from normotensive pregnant women and pre- eclamptic women exert distinct changes on cellular metabolism of calcium $\left(\mathrm{Ca}^{2+}\right)$. There is increase in the intracellular calcium metabolism in normal vascular smooth muscle cells (VSMC) [22]. Normal pregnant sera amplify, whereas pre-eclamptic sera blunt the voltage dependent calcium channels (VDCC).

Atallah et al., suggested the physiological basis behind the development of pre-eclampsia in patients with low calcium intake. They said low intake of calcium stimulates PTH production, which increases the level of intracellular calcium. This causes VSMC contraction leading to hypertension. Thus, calcium supplementation in turn would reduce the level of intracellular calcium and relax the vessels [23]. Some cases have reported that pre-eclampsia exerts severe vasospasm which may cause intrinsic renal changes resulting in severe fall in GFR. This might be responsible for hypocalciuria in pre-eclampsia [17].

Chi square has been used to find significant association (183.13). This finding corresponds with that of Sheela CN et al., [7].

Patrick J Saudan et al., suggested primary or secondary disturbances of renal calcium handling in pre-eclampsia leads to its decreased excretion in urine. Though they found decreased excretion of urinary calcium in pre-eclampsia but lacked the sufficient sensitivity of the test to use it as tool for early diagnosis [24]. Izumi et al., found a limited value of CCR in prediction of preeclampsia [25]. Though the present study calculated the predictive value of CCR but couldn't calculate the sensitivity and specificity.

Estimation of calcium creatinine ratio in a random sample of urine is a simple test. Moreover, the test can be performed easily, hence ensuring patient compliance. It has a good predictive value, hence, justifies the cost. It can therefore be recommended as a screening tool for pre-eclampsia after 20 weeks of gestation in the pregnant women during their antenatal visit. Pre-eclampsia and gestational hypertension is the significant causes of both fetal and maternal morbidity and mortality.

\section{CONCLUSION}

Many tests to predict pre-eclampsia are coming up. So, the present study is intended to identify at risk patient and a selection criteria for primary prevention. In subjects, $89 \%$ of the cases had urinary CCR $\leq 0.04$. The Correlation Coefficient (r), Chi square value showed a significant association. On statistical analysis, it was found that when CCR alone was taken as high risk factor for the early diagnosis of preeclampsia, it was highly significant $p<0.001$.

When high risk factors and urinary calcium creatinine ratio (CCR) were combined then $70 \%$ chance of developing preeclampsia was found. So, this test forms a satisfactory basis for the early diagnosis of pre-eclampsia. The present study showed lower urinary calcium excretion and CCR in preeclamptic than normotensive pregnant women.

Therefore, a single random urinary CCR may be an effective tool for the early diagnosis of pre-eclampsia and may identify population of greatest risk to be included in primary prevention programmes. So, early therapeutic use of calcium may significantly reduce the morbidity and mortality in patients of pre-eclampsia.

\section{REFERENCES}

[1] Gaurang K, Basavraj S, Rudrappa G, Sabithabai T. Study of random urinary calcium - creatinine ratio in prediction of preeclampsia. International Journal of Scientific and Research Publications. 2015; 5( 7):1-3.

[2] Hux YR, Yang Z, Zhonghua F Chan K. Calcium metabolism in preeclampsia. Int J Gynaecology Obstet. 1999; 66(3):245-50.

[3] Urine OCPC method- Giletman HJ 1967 Anal Biochemistry 18:52, clinical Acta 46:46.(5)Harold Varley $4^{\text {th }}$ edition -practical clinical biochemistry Page No: 197-203 (Jaffe's method).

[4] Harold Varley $4^{\text {th }}$ edition -practical clinical biochemistry Page No: 197-203 (Jaffe's method).

[5] Kar J, Srivastava K, Mishra RK et al. Role of urinarycalcium creatinine ratio in prediction of pregnancy induced hypertension. J Obstet Gynaecol India. 2002;52:39-42.

[6] Kazerooni S. and Hamze-Nejadi S. Calcium to creatnine ratio is a spot sample of urine for earlyprediction of pre-eclampsia. Intl J Gynecol Obstet. 2003;80: 279-83.

[7] Sheela CN, Beena SR, Mhaskar A, Calcium-creatinine ratio and microalbuminuria in prediction of preeclampsia. Journal of Obstetrics and Gynaecology of India. 2011:72-76.

[8] Lakshmi NV, Kiranmai P,Ambika K, Rao R. Role of urinary calcium creatinine ratio in prediction of pregnancy induced hypertension. J Int J Pharm Bio Sci. 2013;4(3):(B) 1021 -26.

[9] Ye Y, Dai S, Geng X, Predictive value of urinary calcium measurement on occurrence of pregnancy-induced hypertension. Zhongua Fu Chan Ke Za Zhi. 1995; 30(11): 668-69.

[10] Shilpa M, Shaikh MKS, Thakur, Jain D. Calcium/creatinine ratio in spot urine sample for early detection of preeclampsia. Journal of Evolution of Medical and Dental Sciences. 2014; 3(4): 966-71.

[11] Kazemi AFN, Sehhatie F, Sattarzade $N$ and Mameghani ME. The predictive value of urinary calcium to creatinine ratio, rollover test and BMI in early diagnosis of pre-eclampsia. Research Journal of Biological Sciences. 2010; 5(2):183-86.

[12] Taufield PA, Ales KL, Resnick LM, et al. Hypocalciuria in preeclampsia. N Engl J Med. 1987;316:715-18.

[13] Tufan B et al. Urine calcium excretion in preeclampsia. TKI in J Gynaecol Obst. 2000; 10:29.

[14] Segovia BL, Vega IT, Villarreal EC et al. Hypocalciuria during pregnancy as a riskfactor of preeclampsia. Ginecol Obstet Mex. 2004;72:570-74. 
[15] Ingec M, Nazik H, Kadanali S. Urinary calcium excretion in severe preeclampsia and eclampsia. Clin Chem Lab Med. 2006;44:5153.

[16] Halhali A, Diaz L, Avila $E$ et al. Decreased fractionalurinary calcium excretion and serum, 1,25-dihydroxyvitamin D and IGF-levels in preeclampsia. J Steroid Biochem Mol Biol. 2007; 103:803-06.

[17] Dasgupta M, Adhikari S, Sanghmita M. Urinary calcium levels in pre-eclampsia.IndianJ Obstet Gynaecol 2008;58: 308-13.

[18] Sirohiwal D, Dahiya K, Khaneja N. Use of 24-hour urinary protein and calcium for prediction of preeclampsia. Taiwan J Obstet Gynecol. 2009;48:113-15.

[19] Donovan A et al. Hypocalciuria in pre-eclampsia and gestational hypertension due to decreased fractional excretion of calcium. Arch Med Sci. 2009; 5(1): 80-85.

[20] Phyllis A. Taufield MD, et al. Hypocalciuria in pre-eclampsia. New England Journal of Medicine.1987:316 (12):715-18.
[21] Moni SY, Rashid M, Begum HA, Ara S, Ahmed N. Role of calcium therapy on urinary calcium/creatinine ratio in healthy pregnant women and pre-eclamptic women. Bangladesh $J$ Physiol Pharmacology. 2009; 25 (1\&2): 07-09.

[22] Green J, Assady S, Nakhoul F et al. Differential effects of sera from normotensive and hypertensive pregnant women on $\mathrm{Ca} 2+$ metabolism in normal vascular smooth muscle cells. J Am Soc Nephrol. 2000;11:1188-98.

[23] Atallah AN, Hofmery GJ, Duley. The Cochrane Database of Systematic Rewiews. 2004; 2.

[24] Patricia A et al. Reduced urinary calcium/creatinine ratio precedes preeclampsia and intrauterine growth restriction. Journal of Maternal-Fetal Investigation. 1997;7: 163-65.

[25] Izumi A, Minakami $H$, Kuwata T et al. Calcium-to creatinine ratio in spot urine samples in early pregnancy and its relation to the development of preeclampsia. Metabolism.1997; 46:107-08.

\section{AUTHOR(S):}

1. Dr. Indu Prasad

2. Dr. Bandana Kumari

3. Dr. Achal Narayan Roy

4. Dr. Pritam Prakash

\section{PARTICULARS OF CONTRIBUTORS:}

1. Senior Resident, Department of Biochemistry, IGIMS Patna, India.

2. Senior Resident, Department of Biochemistry, IGIMS Patna, India.

3. Professor and Head, Department of Biochemistry, $\mathrm{PMCH}$, Patna, India.
4. Assistant Professor, Department of Biochemistry, $\mathrm{NMCH}$, Patna, India.

\section{NAME, ADDRESS, E-MAIL ID OF THE CORRESPONDING AUTHOR:}

Dr. Indu Prasad,

B-303, Luv Kush Apartment, Siddharth Nagar, Jagdeopath, Bailey Road, Patna-800014, India.

E-mail: drindupd@gmail.com

FINANCIAL OR OTHER COMPETING INTERESTS: None. 